\title{
Immune activity and biodistribution of polypeptide K237 and folic acid conjugated amphiphilic PEG-PLGA copolymer nanoparticles radiolabeled with ${ }^{99 \mathrm{~m} T c}$
}

\author{
Zelai He ${ }^{1,3, *}$, Xiangyu Zhang ${ }^{4, *}$, Jingwen Huang ${ }^{1,3, *}$, Yufeng Wu ${ }^{5}$, Xuanzhang Huang ${ }^{1}$, \\ Jie Chen ${ }^{1}$, Junyong Xia ${ }^{6}$, Hao Jiang ${ }^{3}$, Jing $\mathbf{M a}^{2}$, Jian $\mathbf{W u}^{1}$ \\ ${ }^{1}$ The Second Affiliated Hospital and Yuying Children's Hospital of Wenzhou Medical University, Wenzhou, China \\ ${ }^{2}$ Ultrasonic Department, Shanghai Songjiang Center Hospital, Shanghai, China \\ ${ }^{3}$ The First Affiliated Hospital of Bengbu Medical College, Bengbu, China \\ ${ }^{4}$ Department of Pathology, Jining No.1 Peoples' Hospital, Jining, China \\ ${ }^{5}$ Department of Internal Medicine, Affiliated Cancer Hospital of Zhengzhou University, Henan Cancer Hospital, Zhengzhou, China \\ ${ }^{6}$ Department of Nuclear Medicine, The Affiliated Provincial Hospital of Anhui Medical University, Hefei, China \\ *These authors contributed equally to this work
}

Correspondence to: Junyong Xia, email: xiabingbing@126.com Hao Jiang, email: jianghao1223@163.com

Jing Ma, email: majing0709@163.com

Jian Wu, email: wzzjian@hotmail.com

Keywords: K237, folate, PEG-PLGA, nanoparticles, biodistribution

Received: July 29, $2016 \quad$ Accepted: October 12, 2016

Published: October 24, 2016

\section{ABSTRACT}

In a previous study, amphiphilic copolymer, polypeptide K237 (HTMYYHHYQHHL) and folic acid (FA) modified poly(ethylene glycol)-poly(lactic-co-glycolic acid) (K237/ FA-PEG-PLGA) nanoparticles were developed and studied as a drug carrier. To further promote the clinical application of K237/FA-PEG-PLGA nanoparticles and provide guidance for future research, we need to examine their specific biodistribution in vivo. In this study, K237/FA-PEG-PLGA nanoparticles were effectively labeled by a direct method with Technetium-99m ( ${ }^{99 \mathrm{~m} T c)}$ using stannous chloride as a reducing agent. The optimal stability of the labeled nanoparticles was determined by evaluating their radiochemical purity in serum, physiological saline, diethylenetriaminepentaacetic acid (DTPA) and cysteine solutions. The affinity of ligands and receptors was elicited by cell binding and blocking experiments in KDR/folate receptor high expressing SKOV-3 ovarian cancer cells. The nanoparticles biodistribution was studied after intravenous administration in healthy mice xenografted with SKOV-3 cells. A higher percent injected dose per gram of tissue ( $\%$ ID/g) was observed in liver, kidney, spleen, blood and tumor at 3 and $9 \mathrm{~h}$ post-injection. Scintigraphic images revealed that the radioactivity was mainly concentrated in tumor, liver, kidney and bladder; and in the heart, lung, and muscle was significantly lower at $\mathbf{3} \mathrm{h}$. The radioactivity distribution in the images is consistent with the in vivo biodistribution data. Our works demonstrated that K237/FA-PEG-PLGA nanoparticles have great potential as biodegradable drug carriers, especially for tumors expressing the folate and $\mathrm{KDr}$ receptor.

\section{INTRODUCTION}

Technetium-99m ( ${ }^{99 \mathrm{~m}} \mathrm{Tc}$; half-life, $6.02 \mathrm{~h} ; \boldsymbol{\gamma}$-energy, $140.5 \mathrm{KeV}$ ) is a commonly used nuclide in biodistribution, drug tracing and molecular imaging applications due to its low cost, excellent availability, little impact on drug biochemical properties, photon energy that is nearly ideal for single-photon emission computed tomography (SPECT) and low absorbed-dose burden to the patients.

In this study, an amphiphilic polymer, namely peptides K237 (HTMYYHHYQHHL) (target the vascular endothelial growth factor receptor-2, abbreviation: VEGFR-2 or KDR) and folic acid (FA) modified poly(ethylene glycol)poly(lactic-co-glycolic acid) (K237/FA-PEG-PLGA), was 
used to prepare nanoparticles (NPs) which can serve as favorable carriers for the delivery of certain drugs [1-4]. In this delivery system, the covalent conjugation of K237 and FA to the NPs confers them the ability to actively bind the KDR receptor and folate receptor (FR). Binding to the receptors leads to a greater uptake of the NPs by KDR/FRoverexpressing tumor cells while virtually ignoring normal tissues, thereby, increasing tumor cell specificity, greatly enhancing antitumor efficacy, and dramatically reducing potentially dangerous side effects [5-8]. Polyethylene glycol (PEG) functions as the outer corona and prolongs the circulation time of the NPs in blood by reducing non-specific interactions with blood components [9-17]. The PLGA hydrophobic component serves as a reservoir for lipophilic drug, while the anionic component provides the ability to strong electrostatic interaction with cationic drugs [18, 19]. However, the biodistribution of K237/FA-PEG-PLGA NPs has not yet been specifically and quantized studied in ovarian cancer model by using radioisotope ${ }^{99 \mathrm{~m}} \mathrm{Tc}$. Accordingly, we used the radioisotope ${ }^{99 \mathrm{~m}} \mathrm{Tc}$ to label the delivery system and study the distribution of radioactivity in various tissues following administration of the labelled NPs by performing gamma imaging of the whole body at predetermined time point.

\section{RESULTS AND DISCUSSION}

\section{Physics characterization of NPs}

The K237/FA-PEG-PLGA NPs have a rigid structure due to ionic interaction among the base amino groups at the amino-terminus of PEG-PLGA. The mean diameter of the K237/FA-PEG-PLGA (LA/GA =60/40, 70/30, 80/20) NPs was $128.7 \pm 13.9,114.6 \pm 10.3$, and $104.2 \pm 9.6 \mathrm{~nm}$, respectively, and the $\zeta$ potential was $-23.53 \pm 2.79$, $-18.71 \pm 1.84$, and $-16.91 \pm 2.08 \mathrm{mV}$, respectively. Meantime, the polydispersity was $0.18 \pm 0.03,0.17 \pm 0.03$ and $0.14 \pm 0.02$. respectively. The mean size and polydispersity index values indicate the narrow size and homogenous distributions of the particles. The $\zeta$ potential values indicate the stability of the nanodispersions. The presence of PEG chains in the outer shell layer was used to improve the stability and biocompatibility of the NPs [20-23]. A TEM photograph, presented in Figure 1, shows that the NPs were approximately round, smooth, uniform size and exhibited no agglomeration. And there were not obvious changes after ${ }^{99 \mathrm{~m}} \mathrm{Tc}$ label NPs.

\section{Radiolabeling of NPs with ${ }^{99 \mathrm{~m}} \mathrm{Tc}$}

The NPs were labeled with ${ }^{99 m} \mathrm{Tc}$ with a high labeling efficiency by a direct method. In the labeling process, the amount of stannous chloride and $\mathrm{pH}$ value were critical factors influencing labeling efficiency. The amount of stannous chloride affected the ratio of reduced/ hydrolyzed $(\mathrm{R} / \mathrm{H}){ }^{99 \mathrm{~m}} \mathrm{Tc}$ and free ${ }^{99 \mathrm{~m}} \mathrm{Tc}$. Thus, higher amounts of stannous chloride could lead to formation of radioactive colloids which are undesirable, while lower amounts of stannous chloride could lead to poor labeling efficiency. The influence of stannous chloride on the labeling efficiency and the $\mathrm{R} / \mathrm{H}$ of ${ }^{99 \mathrm{~m}} \mathrm{Tc}$ is shown in Table 1. In this study, the aim was to determine the optimal amount of stannous chloride required for higher labeling efficiency with lower free ${ }^{99 \mathrm{~m}} \mathrm{Tc}$ and $\mathrm{R} / \mathrm{H}$ of ${ }^{99 \mathrm{~m}} \mathrm{Tc}$. The study found that $20 \mu \mathrm{g}$ was the optimal amount required for all NPs preparations. The optimal $\mathrm{pH}$ value and incubation time of the NPs, which can obtain high labeling efficiency, was 7.0 and $15 \mathrm{~min}$, respectively. To optimize the above parameters, quality control tests were performed by TLC using ITLC strips.

\section{Stability of labeled NPs in vitro}

The ${ }^{99 \mathrm{~m}}$ Tc-labeled NPs were assessed for their stability in vitro after incubation with healthy human serum and $0.9 \% \mathrm{NaCl}$ solutions. These conditions were selected to mimic the in vivo internal environment, physiological $\mathrm{pH}$, in vitro storage and applied environment. The human serum contains many kinds of proteins which can chelate and bind to ${ }^{99 \mathrm{~m}} \mathrm{Tc}$, affect the stability of the labeled NPs in blood when the labeled NPs are injected intravenously. If the labeled NPs were stable in serum, markers can be used for in vivo biodistribution studies.

The labeling efficiency of the three kinds of NPs, namely $\mathrm{LA} / \mathrm{GA}=60 / 40,70 / 30$ and $80 / 20$, in a $0.9 \% \mathrm{NaCl}$ solution was $95.1 \%, 94.26 \%, 93.03 \%$, respectively, at $4 \mathrm{~h}$, and $89.74 \%, 90.63 \%, 90.05 \%$, respectively, at $24 \mathrm{~h}$ (Figure 2A). The labeling efficiency in serum was $94.28 \%$, $94.67 \%, 93.95 \%$, respectively, at $4 \mathrm{~h}$, and $88.94 \%$, $89.53 \%, 88.31 \%$, respectively, at $24 \mathrm{~h}$ (Figure 2B). These results indicate that the three kinds of NPs were quite stable in serum and normal saline within $24 \mathrm{~h}$.

\section{DTPA and cysteine challenge}

The strength of the ${ }^{99 \mathrm{~m}} \mathrm{Tc}$ binding to NPs in ${ }^{99 \mathrm{~m}} \mathrm{Tc}$ labeled NPs was tested with $10,30,50 \mathrm{mM}$ of DTPA or cysteine, which may indirectly confirm that no transchelation of the metal occurred in such physiological environment. The results indicated that the labeling efficiency of the NPs was not altered much in presence of DTPA (Figure 3A) or cysteine (Figure 3B). Indeed, an evaluation of these results revealed that only $1 \%-2 \%$ transchelation occurred when incubated with $10 \mathrm{mM}$ of DTPA or cysteine; while incubation for $1 \mathrm{~h}$ with $50 \mathrm{mM}$ of DTPA or cysteine, the transchelation was only around $4-5 \%$ with DTPA and less than $4 \%$ with cysteine, indicating the high stability of the labeled NPs.

\section{Cell binding and blocking experiments in vitro}

The binding specificity of the ${ }^{99 \mathrm{~m}} \mathrm{Tc}-\mathrm{K} 237 / \mathrm{FA}-\mathrm{PEG}-$ PLGA NPs to the SKOV-3 cell line is shown in Tables 2-4. 
The results of the binding specificity tests indicated that the binding of the ${ }^{99 \mathrm{~m}} \mathrm{Tc}-$ labeled NPs to FR-expressing cells was receptor-mediated, because the receptors could be blocked and their saturation by pre-incubation with an excess of FA can significantly decreased the binding of the radiolabeled NPs. However, the amount of the free ${ }^{99} \mathrm{TcO}_{4}^{-}$binding to cells was negligible. The cell-associated immune activity of the ${ }^{99 \mathrm{~m}}$ Tc-K237/FA-PEG-PLGA (LA/GA = 60/40, 70/30, $80 / 20$ ) NPs binding to the SKOV-3 cell line was $31.75 \%$, $32.79 \%$ and $34.01 \%$, respectively. The highest specific binding rate of the ${ }^{99 \mathrm{~m}} \mathrm{Tc}-\mathrm{K} 237 / \mathrm{FA}-\mathrm{PEG}-\mathrm{PLGA}$ (LA/GA $=60 / 40,70 / 30,80 / 20)$ NPs binding to SKOV-3 cells was $32.28 \%, 34.13 \%, 36.72 \%$, respectively. Additionally, the total and specific binding rates declined with a decrease of the density of the SKOV-3 cells. These results indicate that the labeled NPs have good bioactivity and specificity. Specifically, the ${ }^{99 \mathrm{~m}}$ Tc-K237/FA-PEG-PLGA (LA/GA = 80/20) NPs have the best bioactivation and specificify of the three kinds of NPs evaluated, although the difference was not statistically significant.

\section{In vivo studies}

\section{Biodistribution studies}

Data on the comparative biodistribution of the ${ }^{99 \mathrm{~m}} \mathrm{Tc}-$ labeled NPs in male BALB/c nu/nu mice xenografted with SKOV-3 cells at 3 , and $9 \mathrm{~h}$ are presented in Table 5 . The average radioactivity in the liver, and spleen, was 23.1 and $13.28 \%$, respectively, at $3 \mathrm{~h}$, and 6.50 and $2.45 \%$, respectively, at $9 \mathrm{~h}$. The ${ }^{99 \mathrm{~m}} \mathrm{Tc}-\mathrm{K} 237 / \mathrm{FA}-\mathrm{PEG}-\mathrm{PLGA}$ $(\mathrm{LA} / \mathrm{GA}=80 / 20)$ NPs were found to be mainly concentrated in the mononuclear phagocyte system (MPS). The low level of radioactivity detected in the stomach suggests that the release of ${ }^{99 \mathrm{~m}} \mathrm{Tc}$ in vivo was negligible. The high radioactivity in kidney, indicates that the ${ }^{99 \mathrm{~m}} \mathrm{Tc}$-labeled NPs were mainly metabolized through the urinary system. Meanwhile, the high radioactivity detected in blood, reveals the long cycle effects of the NPs, and suggests that it may be better to target tumors by the enhanced permeability and retention effect (EPR) and the binding of ligand and receptor.

\section{$\gamma$-Camera imaging}

The scintigraphic images of the ${ }^{99 \mathrm{~m}} \mathrm{Tc}-\mathrm{K} 237 / \mathrm{FA}-\mathrm{PEG}-$ PLGA (LA/GA =80/20) NPs were acquired at 3 and $9 \mathrm{~h}$ (Figure 4) after tail vein injection, and confirmed the results of the biodistribution experiments. These images reveal the high level of radioactivity accumulation in tumor, liver, kidney and bladder. The results of the region of interest (ROI), show that the T/NT of tumor and contralateral muscle conforms to the biodistribution experiments. The uptake of radioactivity by the bone marrow of the mice injected with ${ }^{99 m}$ Tc-K237/FA-PEG-PLGA (LA/GA = 80/20) NPs was low. Additionally, compared with the radioactivity accumulation at $3 \mathrm{~h}$, after $9 \mathrm{~h}$ of the tail vein administration of the labeled NPs, the distribution in vivo was the same as the $3 \mathrm{~h}$ and the radioactivity was decreased in the liver, kidney, bladder and tumor.

\section{CONCLUSIONS}

K237/FA-PEG-PLGA NPs with narrow size and homogenous distribution were successfully prepared using the W/O and solvent evaporation method. The NPs loaded
A

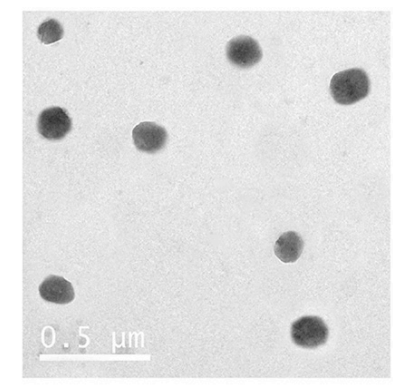

B

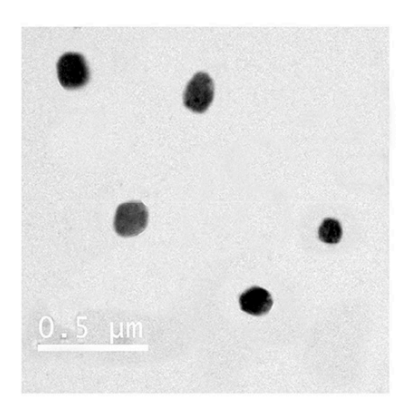

C

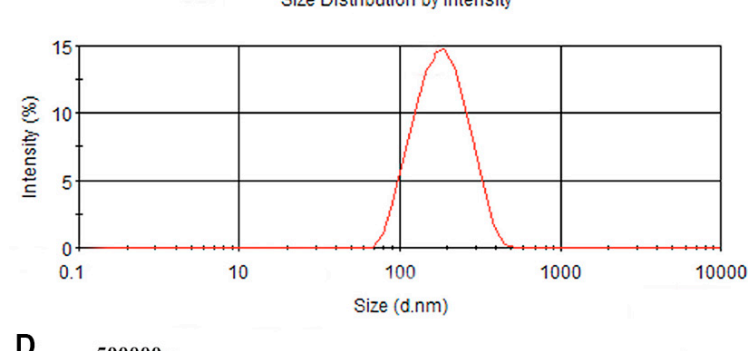

D

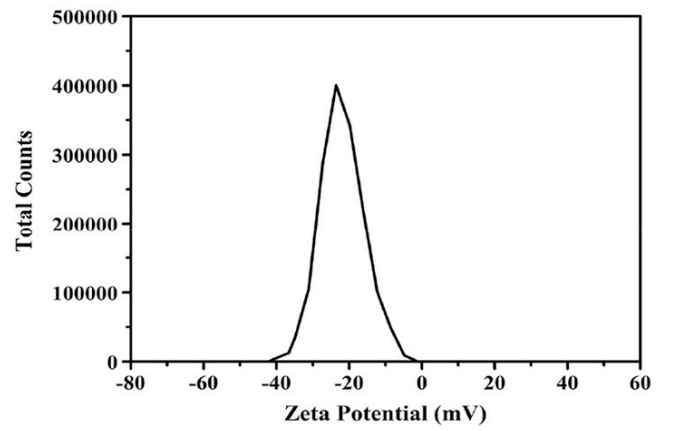

Figure 1: TEM and DLS characterization of the NPs. The K237/FA-PEG-PLGA (LA/GA = 60/40) NPs (A) and ${ }^{99 \mathrm{~m} T c-K 237 /}$ FA-PEG-PLGA (LA/GA = 60/40) NPs $(B)$ are spherical and uniform size. K237/FA-PEG-PLGA (LA/GA=60/40) NPs have a diameter of about $130 \mathrm{~nm}(\mathbf{C})$, and negative zeta potential (D). 
Table 1: Influence of the amount of stannous chloride on the labeling efficiency of NPs

\begin{tabular}{lcccc}
\hline \multicolumn{1}{c}{$\mathbf{S n C l}_{2} \cdot \mathbf{2} \mathbf{H}_{2} \mathbf{O}(\boldsymbol{\mu g})$} & $\mathbf{2 0}$ & $\mathbf{3 0}$ & $\mathbf{5 0}$ & $\mathbf{1 0 0}$ \\
\hline K237/FA-PEG-PLGA (LA/GA = 60/40) & & & & \\
\% Labeled (mean $\pm \mathrm{SD})$ & $97.95 \pm 1.13$ & $95.88 \pm 2.73$ & $94.3 \pm 1.90$ & $86.92 \pm 2.85$ \\
\% colloids (mean $\pm \mathrm{SD})$ & $0.37 \pm 0.35$ & $1.16 \pm 0.87$ & $1.77 \pm 0.55$ & $2.71 \pm 1.83$ \\
\% free (mean $\pm \mathrm{SD})$ & $1.68 \pm 0.44$ & $2.96 \pm 1.07$ & $3.93 \pm 1.61$ & $10.37 \pm 3.32$ \\
K237/FA-PEG-PLGA (LA/GA = 70/30) & & & & \\
\% Labeled (mean $\pm \mathrm{SD})$ & $96.56 \pm 3.66$ & $94.12 \pm 3.12$ & $93.58 \pm 3.16$ & $84.12 \pm 3.24$ \\
\% colloids (mean $\pm \mathrm{SD})$ & $1.08 \pm 0.36$ & $2.03 \pm 0.82$ & $2.37 \pm 1.00$ & $4.06 \pm 2.75$ \\
\% free (mean $\pm \mathrm{SD})$ & $2.36 \pm 1.42$ & $3.75 \pm 1.28$ & $4.05 \pm 0.78$ & $11.82 \pm 2.47$ \\
K237/FA-PEG-PLGA (LA/GA $=80 / 20)$ & & & & \\
\% Labeled (mean $\pm \mathrm{SD})$ & $95.40 \pm 2.29$ & $94.39 \pm 1.93$ & $93.26 \pm 3.19$ & $82.98 \pm 2.70$ \\
\% colloids (mean $\pm \mathrm{SD})$ & $1.73 \pm 0.72$ & $2.099 \pm 0.54$ & $2.56 \pm 0.82$ & $4.75 \pm 2.50$ \\
\% free (mean $\pm \mathrm{SD})$ & $2.87 \pm 0.72$ & $3.52 \pm 1.86$ & $4.18 \pm 2.04$ & $12.27 \pm 3.43$ \\
\hline
\end{tabular}
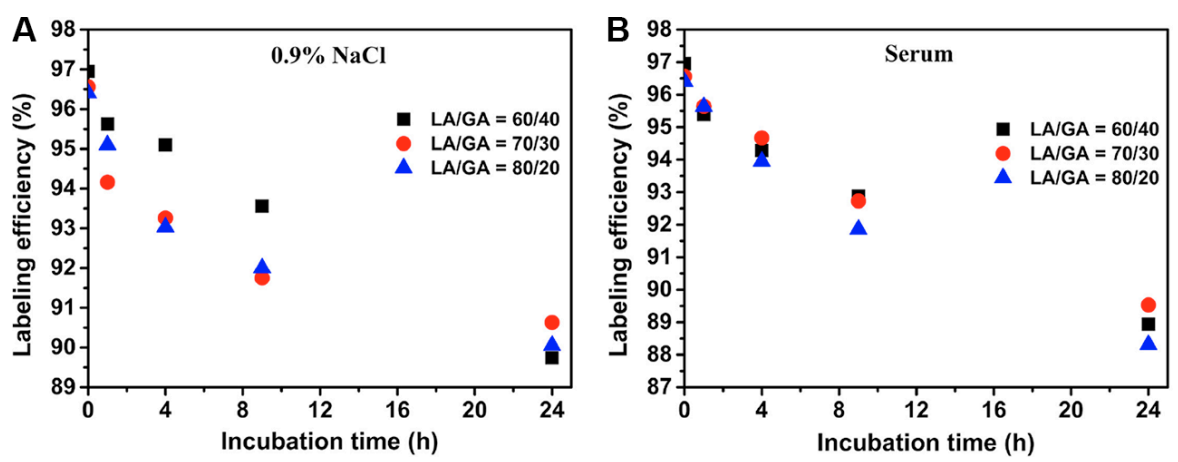

Figure 2: In vitro stability studies of the ${ }^{99 \mathrm{~m}}$ Tc-K237/FA-PEG-PLGA NPs in (A) physiological saline and (B) human serum.
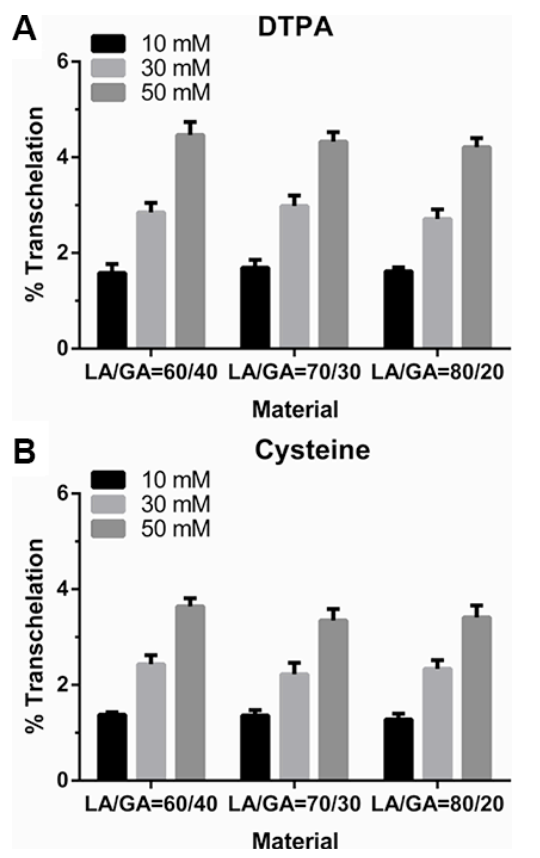

Figure 3: Determination of the in vitro stability of the ${ }^{99 \mathrm{~m}}$ Tc-K237/FA-PEG-PLGA (LA/GA $\left.=60 / 40,70 / 30,80 / 20\right)$ NPs by the (A) DTPA and (B) cysteine challenge test. 
Table 2: The ${ }^{99 \mathrm{~m}}$ Tc-K237/FA-PEG-PLGA (LA/GA = 60/40) NPs binding rate (\%) of SKOV-3 cells

\begin{tabular}{ccccc}
\hline \multirow{2}{*}{$\begin{array}{c}\text { Number of SKOV-3 } \\
\text { cells }\end{array}$} & ${ }^{99 \mathrm{~m}_{\text {TcO4}}{ }^{-}}$ & \multicolumn{3}{c}{ LA/GA $=\mathbf{6 0} / \mathbf{4 0}$} \\
\cline { 3 - 5 } & & Total binding & Non-specific binding & Specific binding \\
\hline $5 \times 10^{6}$ & $2.59 \pm 0.47$ & $36.14 \pm 1.0$ & $3.86 \pm 0.13$ & 32.28 \\
$1 \times 10^{6}$ & $2.30 \pm 0.21$ & $33.41 \pm 0.18$ & $3.57 \pm 0.1$ & 29.84 \\
$1 \times 10^{5}$ & $1.89 \pm 0.53$ & $30.48 \pm 1.10$ & $2.52 \pm 0.32$ & 27.96 \\
$5 \times 10^{4}$ & $1.58 \pm 0.55$ & $25.89 \pm 1.70$ & $1.69 \pm 0.06$ & 24.2 \\
$1 \times 10^{4}$ & $1.62 \pm 0.71$ & $21.37 \pm 1.50$ & $1.74 \pm 0.88$ & 19.63 \\
\hline
\end{tabular}

Table 3: The ${ }^{99 \mathrm{~m} T c-K 237 / F A-P E G-P L G A ~(L A / G A ~=~ 70 / 30) ~ N P s ~ b i n d i n g ~ r a t e ~(\%) ~ o f ~ S K O V-3 ~ c e l l s ~}$

\begin{tabular}{cccc}
\hline \multirow{2}{*}{ Number of SKOV-3 cells } & \multicolumn{3}{c}{ LA/GA = 70/30 } \\
\cline { 2 - 4 } & Total binding & Non-specific binding & Specific binding \\
\hline $5 \times 10^{6}$ & $37.89 \pm 0.67$ & $3.76 \pm 0.21$ & 34.13 \\
$1 \times 10^{6}$ & $35.99 \pm 2.09$ & $3.69 \pm 0.20$ & 32.3 \\
$1 \times 10^{5}$ & $29.65 \pm 1.46$ & $2.93 \pm 0.16$ & 26.72 \\
$5 \times 10^{4}$ & $24.73 \pm 0.50$ & $2.09 \pm 0.03$ & 22.64 \\
$1 \times 10^{4}$ & $20.75 \pm 1.91$ & $1.71 \pm 0.25$ & 19.04 \\
\hline
\end{tabular}

Table 4: The ${ }^{99 \mathrm{~m} T c-K 237 / F A-P E G-P L G A}(\mathrm{LA} / \mathrm{GA}=\mathbf{8 0} / 20)$ NPs binding rate $(\%)$ of SKOV-3 cells

\begin{tabular}{cccc}
\hline \multirow{2}{*}{ Number of SKOV-3 cells } & \multicolumn{3}{c}{ LA/GA = 80/20 } \\
\cline { 2 - 4 } & Total binding & Non-specific binding & Specific binding \\
\hline $5 \times 10^{6}$ & $40.56 \pm 2.31$ & $3.84 \pm 0.47$ & 36.72 \\
$5 \times 10^{5}$ & $33.08 \pm 0.57$ & $3.34 \pm 0.40$ & 29.74 \\
$1 \times 10^{5}$ & $29.95 \pm 1.52$ & $2.83 \pm 0.02$ & 27.12 \\
$5 \times 10^{4}$ & $27.17 \pm 1.08$ & $2.26 \pm 0.06$ & 24.91 \\
$1 \times 10^{4}$ & $21.85 \pm 0.82$ & $1.92 \pm 0.79$ & 19.93 \\
\hline
\end{tabular}

Table 5: Biodistribution of the ${ }^{99 m}$ Tc-labeled NPs in male BALB/c nu/nu mice bearing SKOV-3 Xenografts, at 3 and 9 hours after intravenous injection

\begin{tabular}{ccccc}
\hline \multirow{2}{*}{ Organ } & \multicolumn{2}{c}{ Uptake (\% ID/g) } & \multicolumn{2}{c}{ Tumor-to-organ ratio } \\
\cline { 2 - 5 } & $\mathbf{3 ~ h}$ & $\mathbf{9} \mathbf{h}$ & $\mathbf{3 ~ h}$ & $\mathbf{9} \mathbf{h}$ \\
\hline Liver & $23.1 \pm 1.84$ & $6.50 \pm 1.11$ & 0.92 & 0.95 \\
Kidney & $22.73 \pm 2.90$ & $6.23 \pm 0.96$ & 0.93 & 0.99 \\
Spleen & $13.28 \pm 0.81$ & $2.45 \pm 0.69^{*}$ & 1.6 & 2.51 \\
Blood & $13.18 \pm 0.42^{*}$ & $2.20 \pm 0.66^{*}$ & 1.61 & 2.79 \\
Stomach & $4.31 \pm 0.20^{*}$ & $0.89 \pm 0.39$ & 4.93 & 6.9 \\
Lung & $0.88 \pm 0.04^{*}$ & $0.16 \pm 0.06^{*}$ & 24.16 & 38.38 \\
Tumor & $21.26 \pm 1.27$ & $6.14 \pm 1.45$ & - & - \\
Bone & $0.48 \pm 0.14^{*}$ & $0.07 \pm 0.03^{* *}$ & 44.29 & 87.71 \\
Thyroid & $0.44 \pm 0.02^{*}$ & $0.12 \pm 0.04^{* *}$ & 48.32 & 51.17 \\
Heart & $0.41 \pm 0.12^{*}$ & $0.09 \pm 0.02^{* *}$ & 51.85 & 68.22 \\
Intestines & $0.40 \pm 0.14^{*}$ & $0.11 \pm 0.04^{*}$ & 53.15 & 55.82 \\
Muscle & $0.23 \pm 0.07^{*}$ & $0.04 \pm 0.01^{* *}$ & 92.44 & 153.5 \\
\hline
\end{tabular}

${ }^{*}$ Significant difference of the $\% \mathrm{ID} / \mathrm{g}$ between tumor and other organs $(p<0.05)$.

${ }^{* *}$ Significant difference of the $\% \mathrm{ID} / \mathrm{g}$ between tumor and other organs $(p<0.01)$.

$\% \mathrm{ID} / \mathrm{g}=$ percent injected dose per gram of tissue. 
with drug were also prepared using a similar method [24]. These approaches can be an alternative to improve the stability and solubility of drug, while enhancing the absorption and bioavailability of the loaded-drug by tumors. The K237/FA-PEG-PLGA NPs were labeled with ${ }^{99 \mathrm{~m}} \mathrm{Tc}$ using a rapid and simple direct labeling procedure to achieve high labeling efficiency and stability within 24 h. Relatively high radioactivity were observed in blood, liver, kidney and tumor after i.v. administration, and high retention in blood were advantageous to increase the loaded-drug residence time. Scintigraphic images showed that the maximum uptake occurred in liver, kidney and tumor. In conclusion, the NPs could be a potential ideal drug delivery system (DDS) to improve the efficacy of the loaded-drug and reduce drug-associated toxic and side effects during cancer treatment.

\section{MATERIALS AND METHODS}

\section{Materials}

PEG, molecular weight (Mw) 2000, was obtained from Sigma-Aldrich Co., Ltd. (Shanghai, China). L-lactide and glycolide were purchased from Yuanshengrong Company (Beijing, China). Pluronic 188 (F68) was obtained from BASF (Ludwigshafen, Germany). Dialysis bags (MWCO 3500 Da) were purchased from Qcbio Science \& Technologies Co., Ltd (Shanghai, China). N-hydroxysuccinimide (NHS) and 1,3-diisopropylcarbodiimide (DIC) were from Meloney Biotechnology Co., LTD (Dalian, China). FA was purchased from Mr. Ng Biological Technology Co., LTD (Nanjing, China). K237 peptide (HTMYYHHYQHHL)

A
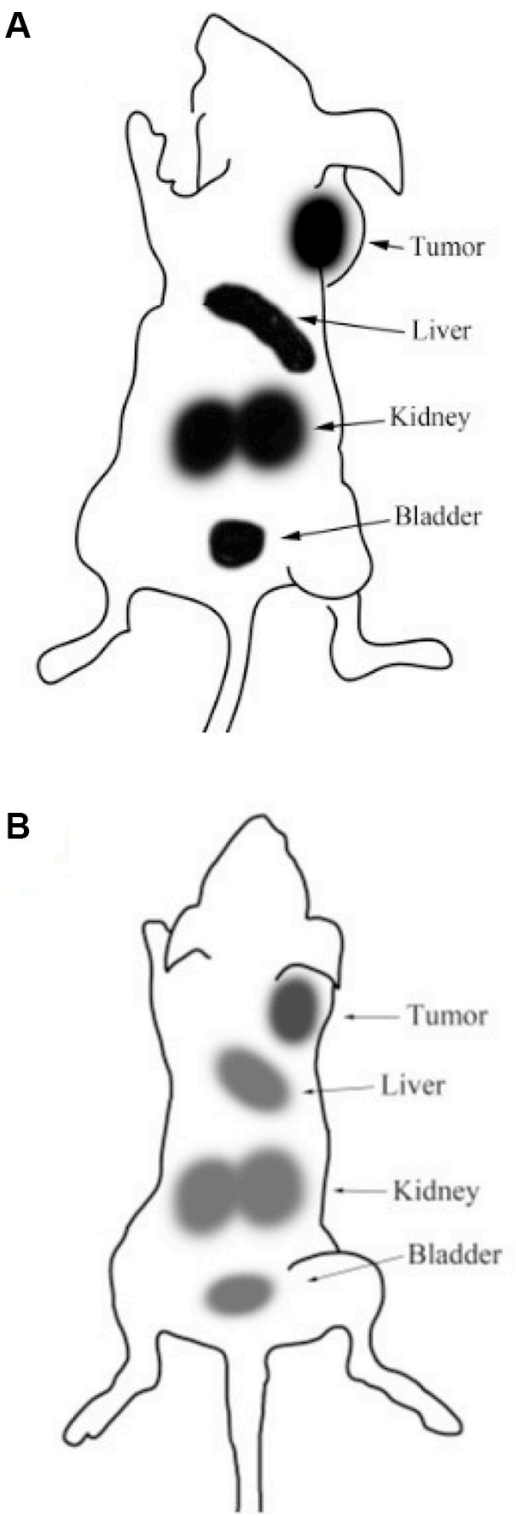

Figure 4: $\gamma$-scintigraphic image of the SKOV3-bearing mice after 3 hours (A) and 9 hours (B) of the i.v. injection of 99mTc-K237/FA-PEG-PLGA (LA/GA = 80/20) NPs. 
was synthesized by GL Biochem Ltd (Shanghai, China). Silica gel for thin-layer chromatography was from Qingdao Haiyang Chemical Co, Ltd (Qingdao, China). Diethylenetriaminepentaacetic acid (DTPA) and cysteine were obtained from Shanghai Yingrui Chemical Technology $\mathrm{CO}$, Ltd (Shanghai, China). Cell culture media and reagents were purchased from Gibco (Grand Island, NY, USA), unless otherwise indicated. Dicyclohexylcarbodiimide (DCC), 4-dimethylaminopyridine (DMAP), $\mathrm{SnCl}_{2}$, ethyl acetate and other reagents and solvents were from Sinopharm Chemical Reagent Co, Ltd (Shanghai, China).

\section{Cells culture and animals}

The SKOV-3 (ovarian cancer cell) were cultured in Dulbecco's modified Eagle's medium (DMEM) (Gibco) supplemented with $10 \%$ fetal bovine serum (FBS), $100 \mathrm{U} / \mathrm{mL}$ penicillin and $100 \mu \mathrm{g} / \mathrm{mL}$ streptomycin, at a $37^{\circ} \mathrm{C}$, in a humidified atmosphere of 5\% $\mathrm{CO}_{2}$ [25-27].

Healthy 4-6 week old male nude Balb/c mice (body weight: $20 \pm 3.5 \mathrm{~g}$ ) were obtained from the Fudan University. All experimental procedures were approved by the Animal Care and Use Committee at the Fudan University.

\section{Synthesis of the K237/FA-PEG-PLGA polymer}

The synthesis of the K237/FA-PEG-PLGA (LA/ $\mathrm{GA}=60 / 40,70 / 30,80 / 20)$ polymer $(\mathrm{Mw} 12,000)$ has been described in detail elsewhere [28-31], following the steps depicted in Scheme 1. In brief, (1) the hydroxylterminated PEG-PLGA was synthesized; (2) the hydroxyl end-group was then converted to Boc- $-\mathrm{Phe}$; (3) the t-Butoxycarbonyl end-group was removed, followed by the synthesis of the amino-terminated PEG-PLGA; (4) the amino-terminated PEG-PLGA $(200 \mu \mathrm{mol})$ was dissolved in DMSO $(60 \mathrm{~mL})$, then mixed with NHS $(1,000 \mu \mathrm{mol})$, DIC $(1,000 \mu \mathrm{mol}), \mathrm{K} 237(500 \mu \mathrm{mol})$ and FA $(500 \mu \mathrm{mol})$ at $37^{\circ} \mathrm{C}$. Following 24 hours incubation, the solution was mixed with $200 \mathrm{~mL}$ of distilled water and centrifuged at $3000 \mathrm{rpm}$. The supernatant was then collected, dialyzed and freeze-dried. The obtained product was dissolved in DMSO and the concentration of the conjugated k237/FA was determined. Various concentrations of K237/FA in DMSO were used as reference.

\section{Preparation of K237/FA-PEG-PLGA NPs}

The K237/FA-PEG-PLGA NPs were prepared using a water in oil (W/O) emulsion method. Briefly, $4 \mathrm{mg}$ of K237/FA-PEG-PLGA were dissolved in $200 \mu \mathrm{L}$ of ethyl acetate, followed by the addition of $2.0 \mathrm{ml}$ of deionized water containing $1 \%(\mathrm{~W} / \mathrm{W})$ of F68. Subsequently, the mixture was homogenized and emulsified by ultrasonication $(400 \mathrm{~W}, 6$ times $\times 10$ s) with a JY 92-II ultrasonic processor (Ningbo Scientz Biotechnology Co, Ltd, China). The resulting emulsion was rotated and evaporated under $0.5 \mathrm{MPa}$ and $37^{\circ} \mathrm{C}$. After $30 \mathrm{~min}$, the emulsion was stirred gently at room temperature to evaporate the left organic solvent. Finally, the NPs were isolated by centrifugation at $15000 \mathrm{rpm}$, at $4^{\circ} \mathrm{C}$ for $30 \mathrm{~min}$, and the pelleted NPs were freeze dried $[32,33]$.

\section{Physical characterization}

The particle size and zeta potential ( $\zeta$ ) of the K237/ FA-PEG-PLGA NPs were characterized using a ZetaSizer Nano ZS (Malvern Instruments Ltd., Malvern, UK). The average diameters and size distribution parameters of the NPs were obtained by dynamic light scattering. The $\zeta$ was determined under a He-Ne laser beam at a wavelength of $633.8 \mathrm{~nm}$ at room temperature.

The morphology of the NPs was examined with an H-800 transmission electron microscope (TEM) from Hitachi Ltd., (Tokyo, Japan). The samples were prepared by depositing $10 \mu \mathrm{L}$ of NPs suspension on a 200 mesh, copper grid with a formvar film, and then air-drying at room temperature [34-37].

\section{Radiolabeling of K237/FA-PEG-PLGA NPs with ${ }^{99 \mathrm{~m}} \mathrm{Tc}$}

Radiolabeling of the NPs was performed by a direct method using stannous chloride as a reducing agent. The effect of the amount of NPs and stannous chloride, the final $\mathrm{pH}$ of the preparation and the incubation time on the labeling efficiency was previously optimized by changing a parameter at a time and by performing quality-control tests for the labeled complex as described earlier [38]. The amount of stannous chloride required for high labeling efficiency and low radio colloids was optimized in preliminary experiments, whereby it was determined that a range of 20 to $100 \mu \mathrm{g}$ of stannous chloride was optimal and thus was used in further experiments. Similarly to achieve optimal labeling efficiency, the amount of NPs, the $\mathrm{pH}$ of the reaction mixture and the incubation time were also investigated. Eventually, the most appropriate labeling protocol was found and can be described as follows. Briefly, $250 \mu \mathrm{L}$ of NPs dispersion $(2 \mathrm{mg} / \mathrm{mL})$ were mixed separately with $20 \mu \mathrm{g}$ of stannous chloride $(40 \mathrm{mg} / \mathrm{mL})$. After adjusting the $\mathrm{pH}$ of the mixture to 7.0 with sodium hydrogen carbonate $(0.5 \mathrm{M}), 50 \mu \mathrm{L}$ of a ${ }^{99} \mathrm{TcO}_{4}$ - solution $(0.74-3.7 \mathrm{GBq})$, freshly eluted from a ${ }^{99} \mathrm{Mo}-{ }^{99 \mathrm{~m}} \mathrm{Tc}$ generator (Drytec, GE Healthcare), was added to each preparation, mixed gentle, and incubated for $15 \mathrm{~min}$ at room temperature. Final radioactivity concentration present in the preparation was examined using a well-type gamma ray spectrometer (Cobra II Inspector 5003; Canberra Packard Central Europe $\mathrm{GmbH}$, Romania) [39]. 


\section{Determination of labeling efficiency}

The labeling efficiency of the NPs was determined by ascending thin layer chromatography (TLC) using instant thin-layer chromatography (ITLC) strips coated with silica gel and the test temperature was $25^{\circ} \mathrm{C}$. The ITLC strips were used to determine the free ${ }^{99 \mathrm{~m}} \mathrm{Tc}$ and percentage of radio colloids in the preparation. Based on these two parameters, the labeling efficiency of the preparation was calculated [40].

ITLC strips were spotted with $2 \sim 3 \mu \mathrm{L}$ labeled complex at $1 \mathrm{~cm}$ above the bottom. These strips were advanced by using acetone as the mobile phase to determine the percentage of the labeled complex and a solvent $\left(\mathrm{V}_{\text {pyridine }}: \mathrm{V}_{\text {acetic acid }}: \mathrm{V}_{\text {water }}=3: 5: 1.5\right)$ as the mobile phase to determine free ${ }^{99 m} \mathrm{Tc}$ and labeled NPs. The solvent front was allowed to reach to a height of approximately 6 to $8 \mathrm{~cm}$ from the origin. The radioactivity in the strip of $R_{f}$ value $=0.1$ to 1.0 was determined by well-type gamma ray spectrometer. The free ${ }^{99 \mathrm{~m}} \mathrm{Tc}$ present in the preparation migrates to the top portion $\left(\mathrm{R}_{\mathrm{f}}\right.$ value about 0.8 to 1.0$)$ of the ITLC strip, leaving the labeled NPs along with the radio colloids (reduced/hydrolyzed ${ }^{99 \mathrm{~m}} \mathrm{Tc}$ ) at the application point when using acetone as the mobile phase. The presence of radio colloids was determined by developing the ITLC strip using a solution of pyridine: acetic acid: water in volume proportion of $3: 5: 1.5$. The reduced/hydrolyzed ${ }^{99 \mathrm{~m}} \mathrm{Tc}$ present in the preparation remains at the point of application, while both the free ${ }^{99 \mathrm{~m}} \mathrm{Tc}$ and labeled NPs migrate to the front with the solvent front [38]. The labeling efficiency was calculated by using the following equation:

Labeling efficiency $(\%)=\left[\mathrm{B}_{\text {acetone }} /(\mathrm{T}+\mathrm{B})_{\text {acetone }}-\mathrm{T}_{\text {pyridine }}{ }^{\prime}\right.$ $\left.(\mathrm{T}+\mathrm{B})_{\text {pyridine }}\right] \times 100 \%$. Where, $\mathrm{T}$ and $\mathrm{B}$ are the radioactivity counts at the top and bottom of the strip, respectively.

\section{Stability of labeled complexes}

The stability of the ${ }^{99 \mathrm{~m}} \mathrm{Tc}$-labeled NPs was evaluated in vitro in human serum and normal saline by the ascending TLC technique. The freshly labeled complex $(10 \mu \mathrm{L})$ was incubated with freshly collected human serum $(90 \mu \mathrm{L})$ at $37^{\circ} \mathrm{C}$. Following incubations for $1 \mathrm{~h}, 4 \mathrm{~h}, 9 \mathrm{~h}$ and $24 \mathrm{~h}$, the samples were separated by ITLC using the above mentioned solvent systems.

\section{DTPA and cysteine challenge}

The in vitro stability studies of ${ }^{99 \mathrm{~m}} \mathrm{Tc}-$ labeled NPs were performed using DTPA and cysteine as previously reported [24]. Briefly, fresh DTPA and cysteine solutions $(10,30,50 \mathrm{mM}$, each) were prepared in $0.9 \% \mathrm{NaCl}$ solutions. A $500 \mu \mathrm{L}$ volume of the labeled NPs was

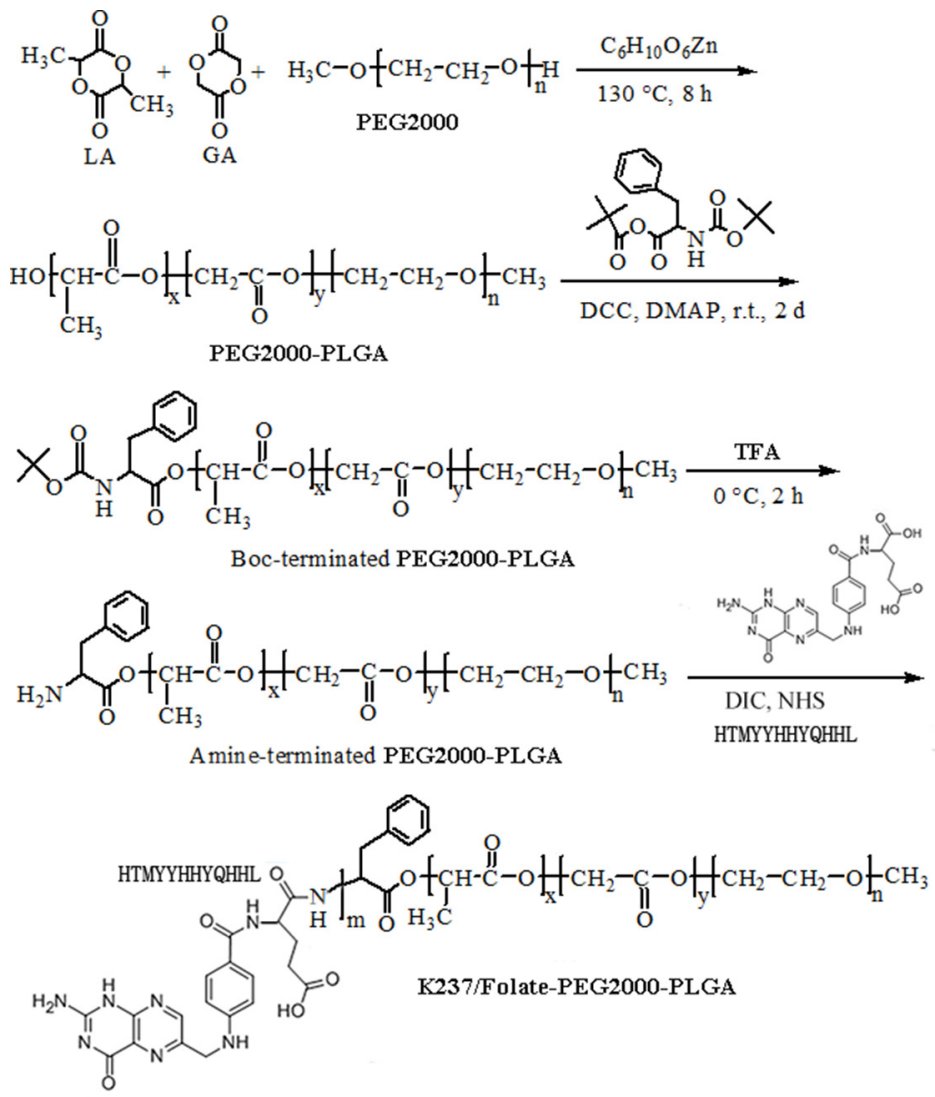

Scheme 1: Schematic depiction of K237/FA-PEG-PLGA copolymer synthesis. 
incubated with the different concentrations of DTPA and cysteine for $1 \mathrm{~h}$ at $37{ }^{\circ} \mathrm{C}$, while a $500 \mu \mathrm{L}$ of $0.9 \%$ $\mathrm{NaCl}$ solution served as control. The effect of DTPA and cysteine on the labeling efficiency of the prepared complexes was analyzed by ITLC-silica gel strips using acetone as mobile phase. In this acetone system, the ${ }^{99} \mathrm{~m}$ Tc-labeled NPs remain at the point of application $\left(R_{f}=0.0\right)$, while free pertechnetate $\left(R_{f}=0.8-1.0\right)$ and all known chemical forms of ${ }^{99 \mathrm{~m} T c-D T P A}$ and ${ }^{99 \mathrm{~m} T c-}$ cysteine complexes migrate upward $\left(\mathrm{R}_{\mathrm{f}}=0.7-1.0\right)$. After developing, each paper was cut into two halves, the top and bottom halves, and radioactivity in each half was measured using a gamma-ray spectrometer [41, 42].

\section{Cell binding and blocking experiments in vitro}

The specificity of the ${ }^{99 \mathrm{~m}} \mathrm{Tc}$-labeled NPs for receptor was assessed in vitro. SKOV-3 cells in the logarithmic phase of proliferation, 80-90\% confluency, were detached with trypsin and resuspended at a cell concentration of $5 \times 10^{6}, 1 \times 10^{6}, 5 \times 10^{5}, 1 \times 10^{5}, 5 \times 10^{4}, 1 \times 10^{4}$ cells $/ \mathrm{mL}$. A volume of $1 \mathrm{~mL}$ of cell suspension was transferred into a centrifuge tube, then $1.5 \mu \mathrm{g}(0.37-2.22 \mathrm{MBq}, 100 \mu \mathrm{L})$ of ${ }^{99 m}$ Tc-K237/FA-PEG-PLGA NPs in DMEM solution was added to each tube, followed by incubation for $1 \mathrm{~h}$ at $37^{\circ} \mathrm{C}$, before the radioactivity count $(\mathrm{T})$ was measured. Cells were collected by centrifugation $(3000 \mathrm{rpm} / \mathrm{min})$ for $10 \mathrm{~min}$, at $4^{\circ} \mathrm{C}$, washed twice with $\mathrm{PBS}(0.01 \mathrm{~mol} / \mathrm{L}$, $\mathrm{pH}=7.4)$, and then the radioactivity of the combination with SKOV-3 cells (B) was measured. Meanwhile, nonspecific binding assay was performed as above described. A total of $191 \mu \mathrm{g}$ of FA (equivalent to 1000 times, compared with FA in $1.5 \mu \mathrm{g}$ nanoparticles) were added to the different cell samples, followed by the addition of the same amount of ${ }^{99 m}$ Tc-K237/FA-PEG-PLGA NPs after incubation for $45 \mathrm{~min}$ at $37^{\circ} \mathrm{C}$. After $1 \mathrm{~h}$, the samples were centrifuged $(3000 \mathrm{rpm} / \mathrm{min}$ ) for $10 \mathrm{~min}$, cells were collected and wash twice with PBS $(0.01 \mathrm{~mol} / \mathrm{L}, \mathrm{pH}=7.4)$, and then the radioactivity was measured. The specific cells binding rate $(\%)=$ the mean of total cells binding rate $(\mathrm{B} / \mathrm{T})$-the mean of non-specific cells binding rate [43-46]. The cells binding rate of the ${ }^{99} \mathrm{TcO}_{4}{ }^{-}$was determined as


was added to the cells suspension solution, then the other steps were as described above.

\section{In vivo studies}

\section{Biodistribution studies}

Previous studies have revealed that K237/FA-PEGPLGA (LA/GA = 80/20) has better physicochemical properties and biocompatibility [27-30, 47-49]. Accordingly, the tumor-targeting properties of the preparations with the most favorable biodistribution, K237/FA-PEG-PLGA (LA/GA = 80/20) NPs was studied in mice xenografted with SKOV-3 cells. For inoculation,
SKOV-3 cells $\left(1 \times 10^{6}\right)$ were implanted in the right hind leg of immunodeficient mice [50-52]. Additionally, 3.7 $\mathrm{MBq}$ of ${ }^{99 \mathrm{~m}}$ Tc-labeled K237/FA-PEG-PLGA $(\mathrm{LA} / \mathrm{GA}=80 / 20) \mathrm{NPs}$ in $150 \mu \mathrm{L}$ of normal saline were administered into the mice tail vein. At $3 \mathrm{~h}$ and $9 \mathrm{~h}$ postinjection mice were sacrificed by cervical dislocation and tissue were dissected for measurement of biodistribution and tumor targeting. The radioactivity associated with the blood, heart, liver, kidney, tumor, lung, spleen, stomach, muscle, and bone tissues were examined with a gamma counter, together with a standard radioactive solution of known quantity administered at the time of each injection, which was considered as $100 \%$. The radioactivity present in each tissue sample was expressed as percent injected dose per gram of tissue $(\% \mathrm{ID} / \mathrm{g})(n=6)[53,54]$.

\section{$\gamma$-Camera imaging}

In vivo imaging was performed to obtain a visual confirmation of the biodistribution data. The SKOV-3 xenograft-bearing mice were injected with $100 \mu \mathrm{Ci}$ of 99m Tc-K237/FA-PEG-PLGA (LA/GA = 80/20) NPs. Before imaging, mice were anesthetized with a mixture of 18.75 $\mathrm{mg} / \mathrm{kg}$ ketamine hydrochloride and $0.5 \mathrm{mg} / \mathrm{kg}$ medetomidine hydrochloride. The accumulation of radioactivity in mice was monitored by imaging with a $\gamma$-camera (GE Healthcare, Cleveland, OH, USA) equipped with a low-energy highresolution collimator. Static images were obtained by a $512 \times 512$ matrix and a pixel side length of $0.4 \mathrm{~mm}$, resulting in a total imaging time of 757 seconds. [55-58]

\section{Statistics}

Statistical analysis was performed using the SPSS 20.0 software (IBM Corp., Armonk, NY, USA). All results are expressed as mean \pm standard deviation (SD) for the values obtained from a minimum of three independent experiments. All statistical analyses involving comparisons of multiple groups were performed using the one-way analysis of variance (ANOVA) and Tukey's post hoc test. All tests were considered statistically significant when the $P$ value was less than 0.05 .

\section{CONFLICTS OF INTEREST}

The work was supported by the funding from Wenzhou Science \& Technology Bureau (No. Y20150049) and NSFC projects (No. 81602727 and No. 81501483).

\section{REFERENCES}

1. Wang H, Xie H, Wu J, Wei X, Zhou L, Xu X, Zheng S. Structure-based rational design of prodrugs to enable their combination with polymeric nanoparticle delivery platforms for enhanced antitumor efficacy. Angew Chem Int Ed Engl. 2014; 53:11532-11537. 
2. Li YJ, Dong M, Kong FM, Zhou JP. Folate-decorated anticancer drug and magnetic nanoparticles encapsulated polymeric carrier for liver cancer therapeutics. Int J Pharm. 2015; 489:83-90.

3. Singh R, Kesharwani P, Mehra NK, Singh S, Banerjee S, Jain NK. Development and characterization of folate anchored Saquinavir entrapped PLGA nanoparticles for antitumor activity. Drug Dev Ind Pharm. 2015; 41:1888-1901.

4. Wei K, Peng X, Zou F. Folate-decorated PEG-PLGA nanoparticles with silica shells for capecitabine controlled and targeted delivery. Int J Pharm. 2014; 464:225-233.

5. Shen J, Putt KS, Visscher DW, Murphy L, Cohen C, Singhal S, Sandusky G, Feng Y, Dimitrov DS, Low PS. Assessment of folate receptor- $\beta$ expression in human neoplastic tissues. Oncotarget. 2015; 6:14700-14709. doi: 10.18632/oncotarget.3739.

6. Fan Shi, Aaron M. Coffey, Kevin W. Waddell, Eduard Y. Chekmenev, Boyd M. Goodson. Nanoscale Catalysts for NMR Signal Enhancement by Reversible Exchange. The Journal of Physical Chemistry C. 2015; 119:7525-7533.

7. Takuya Iwamoto, Yuta Ogawa, Lina Sun, Matthew Schuette White, Eric Daniel Glowacki, Markus Clark Scharber, Niyazi Serdar Sariciftci, Kazuhiro Manseki, Takashi Sugiura, Tsukasa Yoshida. Electrochemical Self-Assembly of Nanostructured CuSCN/Rhodamine B Hybrid Thin Film and Its Dye-Sensitized Photocathodic Properties. The Journal of Physical Chemistry C. 2014; 118:16581-16590.

8. Wang H, Yin H, Yan F, Sun M, Du L, Peng W, Li Q, Feng Y, Zhou Y. Folate-mediated mitochondrial targeting with doxorubicin-polyrotaxane nanoparticles overcomes multidrug resistance. Oncotarget. 2015; 6:2827-2842. doi: 10.18632/oncotarget.3090.

9. $\mathrm{Hu}$ X, Gong X. A new route to fabricate biocompatible hydrogels with controlled drug delivery behavior. J Colloid Interface Sci. 2016; 470:62-70.

10. Wang H, Xie H, Wu J, Wei X, Zhou L, Xu X, Zheng S. Structure-based rational design of prodrugs to enable their combination with polymeric nanoparticle delivery platforms for enhanced antitumor efficacy. Angew Chem Int Ed Engl. 2014; 53:11532-11537.

11. Gong X, Gao C. Influence of salt on assembly and compression of PDADMAC/PSSMA polyelectrolyte multilayers. Phys Chem Chem Phys. 2009; 11:11577-11586.

12. Wang J, Wang H, Li J, Liu Z, Xie H, Wei X, Lu D, Zhuang R, $\mathrm{Xu}$ X, Zheng S. iRGD-Decorated Polymeric Nanoparticles for the Efficient Delivery of Vandetanib to Hepatocellular Carcinoma: Preparation and in Vitro and in Vivo Evaluation. ACS Appl Mater Interfaces. 2016; 8:19228-19237.

13. Huang Y, Jiang Y, Wang H, Wang J, Shin MC, Byun Y, He H, Liang Y, Yang VC. Curb challenges of the "Trojan Horse" approach: smart strategies in achieving effective yet safe cell-penetrating peptide-based drug delivery. Adv Drug Deliv Rev. 2013; 65:1299-1315.

14. Yu Z, Xu Q, Dong C, Lee SS, Gao L, Li Y, D'Ortenzio M, Wu J. Self-Assembling Peptide Nanofibrous Hydrogel as a Versatile Drug Delivery Platform. Curr Pharm Des. 2015; 21:4342-4354.
15. Yu Z, Cai Z, Chen Q, Liu M, Ye L, Ren J, Liao W, Liu S. Engineering $\beta$-sheet peptide assemblies for biomedical applications. Biomater Sci. 2016; 4:365-374.

16. Yu Z, Schmaltz RM, Bozeman TC, Paul R, Rishel MJ, Tsosie KS, Hecht SM. Selective tumor cell targeting by the disaccharide moiety of bleomycin. J Am Chem Soc. 2013; 135:2883-2886.

17. Gonzalo Sequeira, Silvia I Vanzulli, Paola Rojas, Caroline Lamb, Lucas Colombo, María May, Alfredo Molinolo, Claudia Lanari. The effectiveness of nano chemotherapeutic particles combined with mifepristone depends on the PR isoform ratio in preclinical models of breast cancer. Oncotarget. 2014; 5:3246-3260. doi: 10.18632/ oncotarget.1922.

18. Olalde, B.; Aizpurua, J. M.; Garcí, A.; Bustero, I.; Obieta, I.; Jurado, M. J. Single-Walled Carbon Nanotubes and Multiwalled Carbon Nanotubes Functionalized with Poly( L-lactic acid ): a Comparative Study. The Journal of Physical Chemistry C. 2008; 112:10663-10667.

19. Taniguchi Y, Kawano K, Minowa T, Sugino T, Shimojo Y, Maitani Y. Enhanced antitumor efficacy of folate-linked liposomal doxorubicin with TGF- $\beta$ type I receptor inhibitor. Cancer Sci. 2010; 101:2207-2213.

20. Chang WC, Tai JT, Wang HF, Ho RM, Hsiao TC, Tsai DH. Surface PEGylation of Silver Nanoparticles: Kinetics of Simultaneous Surface Dissolution and Molecular Desorption. Langmuir. 2016; 32:9807-9815.

21. Liu P, Zhang H, Wu X, Guo L, Wang F, Xia G, Chen B, Yin H, Wang Y, Li X. Tf-PEG-PLL-PLGA nanoparticles enhanced chemosensitivity for hypoxia-responsive tumor cells. Onco Targets Ther. 2016; 9:5049-5059.

22. Okur AC, Erkoc P, Kizilel S. Targeting cancer cells via tumorhoming peptide CREKA functional PEG nanoparticles. Colloids Surf B Biointerfaces. 2016; 147:191-200.

23. Colzani B, Speranza G, Dorati R, Conti B, Modena T, Bruni G, Zagato E, Vermeulen L, Dakwar GR, Braeckmans K, Genta I. Design of smart GE11-PLGA/PEG-PLGA blend nanoparticulate platforms for parenteral administration of hydrophilic macromolecular drugs: synthesis, preparation and in vitro/ex vivo characterization. Int J Pharm. 2016; 511: 1112-123.

24. Zelai He, Zengfang Shi, Wenjie Sun, Jing Ma, Junyong Xia, Xiangyu Zhang, Wenjun Chen, Jingwen Huang. The biosafety of folic acid conjugated amphiphilic PEGPLGA copolymer nanoparticles of co-delivery cisplatin and paclitaxel and the treatment effect for non-small lung cancer. Tumor Biology. 2015; 37:7809-7821.

25. Müller C, Reddy JA, Leamon CP, Schibli R. Effects of the antifolates pemetrexed and CB3717 on the tissue distribution of $(99 \mathrm{~m}) \mathrm{Tc}-\mathrm{EC} 20$ in xenografted and syngeneic tumor-bearing mice. Mol Pharm. 2010; 7:597-604.

26. Reddy JA, Westrick E, Santhapuram HK, Howard SJ, Miller ML, Vetzel M, Vlahov I, Chari RV, Goldmacher VS, Leamon CP. Folate receptor-specific antitumor activity of EC131, a folate-maytansinoid conjugate. Cancer Res. 2007; 67:6376-6382. 
27. He Z, Sun Y, Cao J, Duan Y. Degradation behavior and biosafety studies of the mPEG-PLGA-PLL copolymer. Phys Chem Chem Phys. 2016; 18:11986-1999.

28. He Z, Wang Q, Sun Y, Shen M, Zhu M, Gu M, Wang Y, Duan Y. The biocompatibility evaluation of mPEG-PLGAPLL copolymer and different LA/GA ratio effects for biocompatibility. J Biomater Sci Polym Ed. 2014; 25:943-964.

29. He Z, Sun Y, Wang Q, Shen M, Zhu M, Li F, Duan Y. Degradation and Bio-Safety Evaluation of mPEG-PLGAPLL Copolymer-Prepared Nanoparticles. The Journal of Physical Chemistry C. 2015; 119:3348-3362.

30. He Z, Huang J, Xu Y, Zhang X, Teng Y, Huang C, Wu Y, Zhang X, Zhang H, Sun W. Co-delivery of cisplatin and paclitaxel by folic acid conjugated amphiphilic PEG-PLGA copolymer nanoparticles for the treatment of non-small lung cancer. Oncotarget. 2015; 6:42150-42168. doi: 10.18632/ oncotarget.6243.

31. Snehalatha M, Venugopal K, Saha RN, Babbar AK, Sharma RK. Etoposide loaded PLGA and PCL nanoparticles II: biodistribution and pharmacokinetics after radiolabeling withTc-99m. Drug Deliv. 2008; 15:277-287.

32. Yu Z, Paul R, Bhattacharya C, Bozeman TC, Rishel MJ, Hecht SM. Structural features facilitating tumor cell targeting and internalization by bleomycin and its disaccharide. Biochemistry. 2015; 54:3100-3109.

33. Huang Y, Yang X, Xu T, Kong Q, Zhang Y, Shen Y, Wei Y, Wang G, Chang KJ. Overcoming resistance to TRAILinduced apoptosis in solid tumor cells by simultaneously targeting death receptors, c-FLIP and IAPs. Int J Oncol. 2016; 49:153-163.

34. An FF, Deng ZJ, Ye J, Zhang JF, Yang YL, Li CH, Zheng CJ, Zhang XH. Aggregation-induced near-infrared absorption of squaraine dye in an albumin nanocomplex for photoacoustic tomography in vivo. ACS Appl Mater Interfaces. 2014; 6: 17985-17992.

35. AN, Fei-Fei, YE, Jun, ZHANG, Jin-Feng, YANG, YinLong, ZHENG, Cai-Jun, ZHANG, Xiu-Juan, LIU, Zhuang, LEE, Chun-Sing and ZHANG, Xiao-Hong. Non-blinking, highly luminescent, $\mathrm{pH}$ - and heavy-metal-ion-stable organic nanodots for bio-imaging. Journal of Materials Chemistry B. $2013 ; 1: 3144-3151$.

36. Rui Ding, Xinjun Yu, Peng Wang, Jinnan Zhang, Yan Zhou, Xian Cao, Hong Tang, Neil Ayres, Peng Zhang. Hybrid photosensitizer based on amphiphilic block copolymer stabilized silver nanoparticles for highly efficient photodynamic inactivation of bacteria. RSC Adv. 2016; 6: 20392-20398.

37. Han R, Sun Y, Kang C, Sun H, Wei W. Amphiphilic dendritic nanomicelle-mediated co-delivery of 5-fluorouracil and doxorubicin for enhancedtherapeutic efficacy. J Drug Target. 2016; doi: 10.1080/1061186X.2016.1207649.

38. Vaneycken I, Govaert J, Vincke C, Caveliers V, Lahoutte T, De Baetselier P, Raes G, Bossuyt A, Muyldermans S, Devoogdt N. In vitro analysis and in vivo tumor targeting of a humanized, grafted nanobody in mice using pinhole SPECT/micro-CT. J Nucl Med. 2010; 51:1099-1106.
39. Kakkar D, Tiwari AK, Chuttani K, Kaul A, Singh H, Mishra AK. Comparative evaluation of glutamate-sensitive radiopharmaceuticals: Technetium-99m-glutamic acid andtechnetium-99m-diethylenetriaminepentaacetic acidbis(glutamate) conjugate for tumor imaging. Cancer Biother Radiopharm. 2010; 25:645-655.

40. Reddy LH, Sharma RK, Murthy RS. Enhanced tumour uptake of doxorubicin loaded poly(butyl cyanoacrylate) nanoparticles in mice bearing Dalton'slymphoma tumour. J Drug Target. 2004; 12:443-451.

41. Lin LT, Chang CY, Chang CH, Wang HE, Chiou SH, Liu RS, Lee TW, Lee YJ. Involvement of let-7 microRNA for the therapeutic effects of Rhenium-188-embedded liposomalnanoparticles on orthotopic human head and neck cancer model. Oncotarget. 2016; 7:65782-65796. doi: 10.18632/oncotarget.11666.

42. Jung KH, Lee KH, Paik JY, Ko BH, Bae JS, Lee BC, Sung HJ, Kim DH, Choe YS, Chi DY. Favorable Biokinetic and Tumor-Targeting Properties of 99mTc-Labeled Glucosamino RGD and Effect of Paclitaxel Therapy. J Nucl Med. 2006; 47:2000-2007.

43. Zannetti A, Del Vecchio S, Iommelli F, Del Gatto A, De Luca S, Zaccaro L, Papaccioli A, Sommella J, Panico M, Speranza A, Grieco P, Novellino E, Saviano M,Pedone C, Salvatore M. Imaging of av $\beta 3$ Expression by a Bifunctional Chimeric RGD Peptide not Cross-Reacting with av $\beta 5$. Clinical Cancer Research. 2009; 15:5224-5233.

44. Wållberg H, Orlova A, Altai M, Hosseinimehr SJ, Widström C, Malmberg J, Ståhl S, Tolmachev V. Molecular Design and Optimization of 99mTc-Labeled Recombinant Affibody Molecules Improves Their Biodistribution and Imaging Properties. J Nucl Med. 2011; 52:461-469.

45. Gainkam LO, Huang L, Caveliers V, Keyaerts M, Hernot S, Vaneycken I, Vanhove C, Revets H, De Baetselier P, Lahoutte T. Comparison of the Biodistribution and Tumor Targeting of Two 99mTc-Labeled Anti-EGFR Nanobodies in Mice, Using Pinhole SPECT/Micro-CT. J Nucl Med. 2008; 49:788-795.

46. Liu X, Jiang C, Zhang D, Gao M, Peng F, Huang D, Sun Z, Ni Y, Zhang J, Yin Z. Tumor necrosis targeted radiotherapy of non-small cell lung cancer using radioiodinated protohypericin in amouse model. Oncotarget. 2015; 6: 26400-26410. doi: 10.18632/oncotarget.4568.

47. Shi C, Liu P, Liu X, Feng X, Fu D. The effects of mPEG proportion and $\mathrm{LA} / \mathrm{GA}$ ratio on degradation and drug release behaviors of PLGA-mPEG microparticles. Pharmazie. 2016; 71:243-246.

48. Yan N, Zhang X, Cai Q, Yang X, Zhou X, Wang B, Deng $X$. The Effects of Lactidyl/Glycolidyl Ratio and Molecular Weight of Poly(D,L -Lactide-co-Glycolide) on the Tetracycline Entrapment and Release Kinetics of Drug-Loaded Nanofibers. J Biomater Sci Polym Ed. 2012; 23:1005-1019.

49. Hong Z, Zhang P, Liu A, Chen L, Chen X, Jing X. Composites of poly(lactide-co-glycolide) and the surface modified carbonated hydroxyapatite nanoparticles. J Biomed Mater Res A. 2007; 81:515-522. 
50. Pal I, Dey KK, Chaurasia M, Parida S, Das S, Rajesh Y, Sharma K, Chowdhury T, Mandal M. Cooperative effect of BI-69A11 and celecoxib enhances radiosensitization by modulating DNA damage repair in colon carcinoma. Tumour Biol. 2016; 37:6389-6402.

51. Erdogan S, Yilmaz FM, Yazici O, Yozgat A, Sezer S, Ozdemir N, Uysal S, Purnak T, Sendur MA, Ozaslan E. Inflammation and chemerin in colorectal cancer. Tumour Biol. 2016; 37:6337-6342.

52. Brown RE, Buryanek J, Katz AM, Paz K, Wolff JE. Alveolar rhabdomyosarcoma: morphoproteomics and personalized tumor graft testing further define the biology of PAX3FKHR(FOXO1) subtype and provide targeted therapeutic options. Oncotarget. 2016; doi: 10.18632/oncotarget.10089.

53. Ji Y, Jiang C, Zhang X, Liu W, Gao M, Li Y, Wang J, Wang Q, Sun Z, Jiang X, Yao N, Wang X, Fang Z, Yin Z, Ni Y, Zhang J. Necrosis targeted combinational theragnostic approach using radioiodinated Sennidin A in rodent tumor models. Oncotarget. 2014; 5:2934-2946. doi: 10.18632/ oncotarget. 1728 .

54. Kang CM, Koo HJ, An GI, Choe YS, Choi JY, Lee KH, Kim BT. Hybrid PET/optical imaging of integrin $\alpha \mathrm{V} \beta 3$ receptor expression using a (64)Cu-labeled streptavidin/ biotin-based dimeric RGD peptide. EJNMMI Res. 2015; doi: 10.1186/s13550-015-0140-0.
55. Sun T, Tang G, Tian H, Hu K, Yao S, Su Y, Wang C. Positron emission tomography imaging of cardiomyocyte apoptosis with a novel molecule probe [18F]FP-DPAZn2. Oncotarget. 2015; 6:30579-30591. doi: 10.18632/oncotarget.5679.

56. Blanco VM, Chu Z, LaSance K, Gray BD, Pak KY, Rider T, Greis KD, Qi X. Optical and nuclear imaging of glioblastoma with phosphatidylserine-targeted nanovesicles. Oncotarget. 2016; 7:32866-32875. doi: 10.18632/ oncotarget.8763.

57. Tang C, Tang G, Gao S, Liu S, Wen F, Yao B, Nie D. Radiosynthesis and preliminary biological evaluation of $\mathrm{N}$-(2-[18F]fluoropropionyl)-L-glutamine as a PET tracer for tumor imaging. Oncotarget. 2016; 7:34100-34111. doi: 10.18632/oncotarget.9115.

58. Cui Y, Liu H, Liang S, Zhang C, Cheng W, Hai W, Yin B, Wang D. The feasibility of 18F-AlF-NOTA-PRGD2 $\mathrm{PET} / \mathrm{CT}$ for monitoring early response of Endostar antiangiogenic therapy in human nasopharyngeal carcinoma xenograft model compared with 18F-FDG. Oncotarget. 2016; 7:27243-27254. doi: 10.18632/oncotarget.8402. 